Asian Spine Journal Vol. 6, No. 3, pp 168 177, 2012

http://dx.doi.org/10.4184/asj.2012.6.3.168

\title{
Computer-assisted C1-C2 Transarticular Screw Fixation "Magerl Technique" for Atlantoaxial Instability
}

\author{
Masashi Uehara, Jun Takahashi, Hiroki Hirabayashi, Hiroyuki Hashidate, Nobuhide Ogihara, Keijiro \\ Mukaiyama, Hiroyuki Kato
}

Department of Orthopaedic Surgery, Shinshu University School of Medicine, Matsumoto, Japan

Study Design: A retrospective study.

Purpose: To evaluate the surgical results of computer-assisted C1-C2 transarticular screw fixation for atlantoaxial instability and the usefulness of the navigation system.

Overview of Literature: We used a computed tomography (CT)-based computer navigation system in planning and screw insertion in Magerl's procedure, which provides the most rigid atlantoaxial fusion, to avoid risk of vertebral artery (VA) tear by avoiding high-riding VA during screw insertion.

Methods: Twenty patients who underwent atlantoaxial fusion under the CT-based navigation system were studied. The mean observation period was 33.5 months. The evaluated items included the existence of VA stenosis by preoperative magnetic resonance angiography, surgical time, blood loss volume, Japanese Orthopaedic Association (JOA) score and Ranawat's pain criteria before surgery and at final follow-up, postoperative screw position evaluated by $\mathrm{CT}$, and bony fusion.

Results: The mean operation time was 205 minutes, with the mean blood loss volume of $242 \mathrm{ml}$. The mean JOA score was 11.6 points before surgery and 13.7 at final follow-up. Occipital and/or cervical pain presented before operation was remitted or resolved in all patients. Evaluation of screw insertion by CT revealed correct penetration to atlantoaxial joints, with a perforation rate of $2.6 \%$. There was no complication, including VA tear, and all patients who were followed-up during one year or more after surgery achieved bony fusion. Some subjects who appeared inappropriate for surgery from CT images were assessed as eligible for surgery based on the evaluation results obtained using the navigation system.

Conclusions: It was demonstrated that the CT-based navigation system is an effective support device for Magerl's procedure.

Key Words: Atlantoaxial joint, Atlantoaxial instability, CT-based computer navigation system, C1-C2 transarticular screw fixation

\section{Introduction}

Dorsal transarticular screw fixation of $\mathrm{C} 1 / \mathrm{C} 2$ (Magerl's procedure) for atlantoaxial instability was first described in 1987 by Magerl and Seemann [1]. This is the most biomechanically rigid procedure in use to directly fix the right and left atlantoaxial joints by transarticular screw. However, this method carries the risk of potential injury to the neural or vascular structures due to anatomical position and variation among patients. Thus, during screw insertion, neurovascular safety should be carefully secured. Frameless stereotactic technology was first designed for guidance around unseen lesions in intracranial surgery [2]. Computer-assisted techniques were introduced in spine surgery in the 1990's to improve the accuracy and safety of operative procedures [3,4]. Spinal navigation systems were subsequently developed and

Received Jul 8, 2011; Revised Aug 12, 2011: Accepted Sep 14, 2011

Corresponding author: Jun Takahashi, MD

Department of Orthpaedic Surgery, Shinshu University School of Medicine,

3-1-1 Asahi, Matsumoto-city, Nagano 390-8621, Japan

Tel: +81-263-37-2659, Fax:+81-263-35-8844, E-mail: jtaka@shinshu-u.ac.jp 
clinically applied to achieve safe and accurate instrumentation surgery such as pedicle or transarticular screw insertion and spinal osteotomy, and advantages of this system have been reported [5-10]. We used a computed tomography (CT)-based computer navigation system in planning and screw insertion in Magerl's procedure. The purpose of this study was to evaluate the surgical results during follow-up of computer-assisted C1-C2 transarticular screw fixation for atlantoaxial instability and the usefulness of the CT-based computer navigation system.

\section{Materials and Methods}

After approval by the Investigational Review Board of our hospital, 20 patients ( 8 males, 12 females; mean age, $57.9 \pm 15.4$ years $[$ mean $\pm \mathrm{SD}]$ ) who underwent atlantoaxial fusion by Magerl's procedure using a CT-based navigation system between October 1998 and January 2011 were studied. A frameless stereotactic image-guidance system (Stealth Station and Stealth Station TREON, Medtronic, Sofamor Danek, Memphis, TN, USA) was used in screw placement and fixation of the atlantoaxial joints. All consecutive patients with three months or more of follow-up who underwent atlantoaxial fixation were included in this study.

Diseases of the patients included 11 cases (three males, eight females; mean age, $60.2 \pm 7.6$ years) of rheumatoid arthritis (RA), 5 (4 males, 1 female; mean age, $66.2 \pm 8.5$ years) of traumatic atlantoaxial subluxation (AAS), 2 (2 females; mean age, $47.0 \pm 11.3$ years) of delayed union after dens fracture, a 5-year-old girl with ossiculum terminale, and a 65 -year-old male with Klippel-Feil syndrome. Two screws position planned for patients were judged ineligible for insertion in preoperative planning. A total of 38 screws were inserted for the operated patients (Table 1).

\section{Surgical procedure}

CT images for navigation are taken preoperatively at the reduction position, with or without a halo vest. MR angiography is performed preoperatively, and when unilateral vertebral artery (VA) occlusion is observed, Magerl's screw insertion to the side of the dominant VA is performed with great care. A halo vest is fitted three or four days before surgery and subluxation is reduced under lateral imaging [11]. To position the screws as far as possible on the cranial side, the patient is placed in the supine position with a pillow for head support, a special neckband is fitted around the neck (at the lordosis, to apply pressure to the $\mathrm{C} 2$ spinous process), and conscious reduction is then performed. The upper position of each screw insertion point is confirmed by lateral image. The operation field is prepared by skin incision from the posterior cranial fossa to the 3rd cervical vertebra, the reference frame is then placed at the spinous process of the 3rd cervical vertebra, and multi-level registration is performed $[9,12]$ by marking six points, including tips of spinous processes and the bilateral tip of the inferior facet on the $2 \mathrm{nd}$ and $3 \mathrm{rd}$ cervical vertebrae. An insertion hole is prepared at each screw insertion point using a 3-mm speed drill. Then, a probe is pointed to the insertion hole and a site for a small incision is decided under the navigation image (Fig. 1). At each screw insertion point, a small incision of about $1 \mathrm{~cm}$ is prepared and a guide pin for navigation, drill, and screw is inserted (Fig. 2). Lateral image is also used, and the reduction is performed by an assistant who applies pressure to the spinous process of the 2 nd cervical vertebra when the guide pin penetrates through the joint. Implants used for the procedure were Trans Bone Screw (KiscoMedica, St. Priest, France) in 5 cases, Universal Cannulated Screw Set (UCSS, Medtronic, Sofamor Danek) in 14 cases,

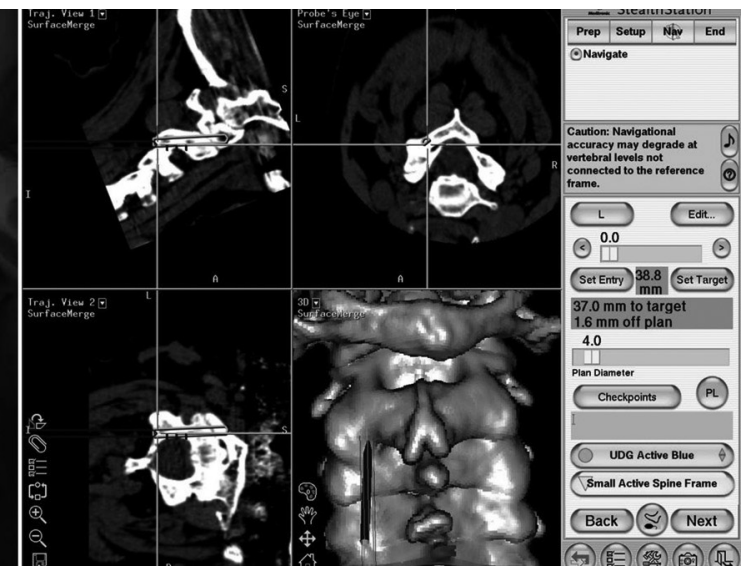

Fig. 1. The direction of screw insertion was determined using a probe, then the screw insertion position was established. 


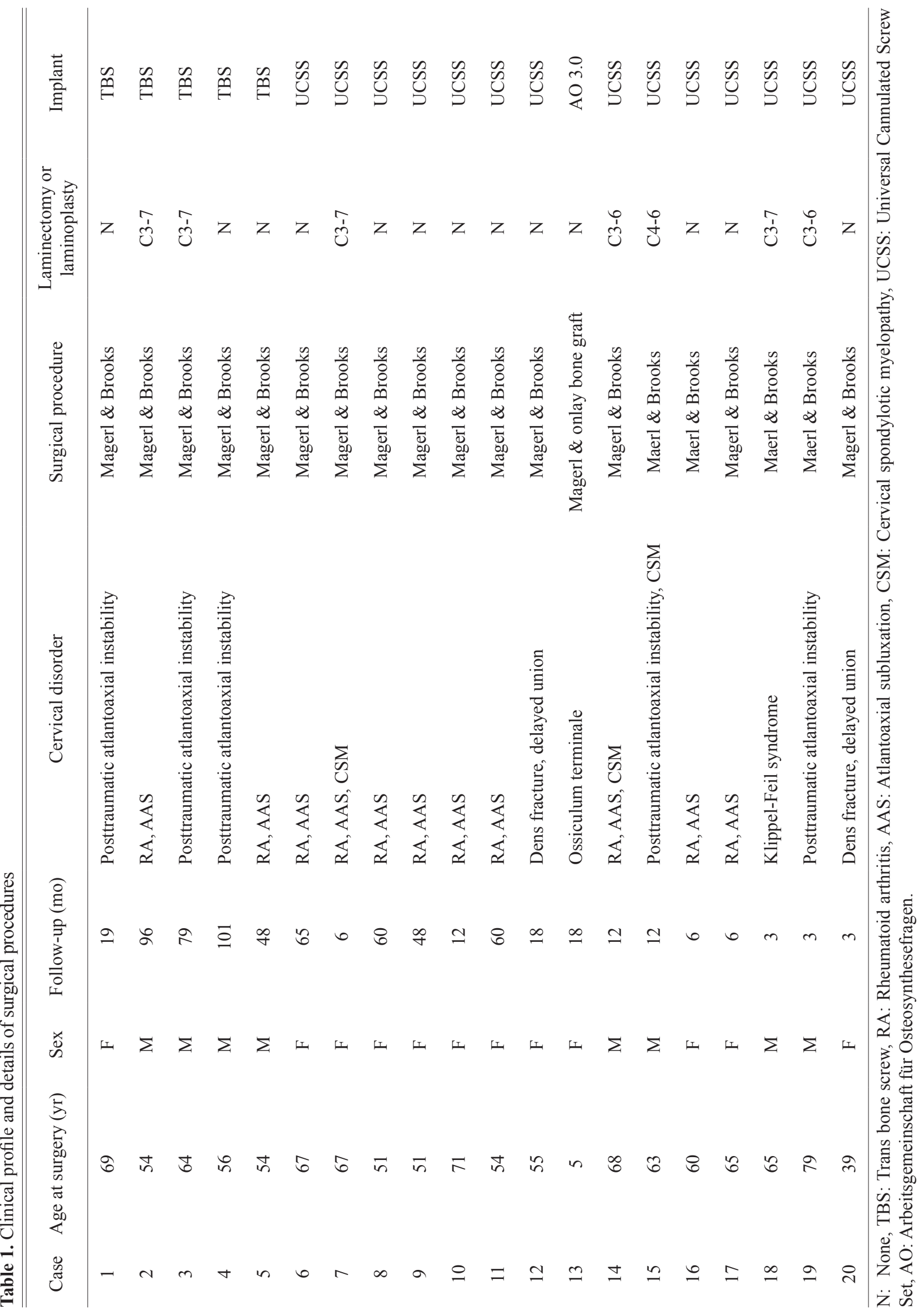


and $3.0 \mathrm{~mm}$ Cannulated Screws (Synthes Inc., West Chester, PA, USA) in 1 case (5-year-old girl). In general, the Brooks method, using a high-molecular weight polyethylene cable, is concomitantly performed. The halo vest is removed immediately after surgery and walking is allowed from the day after surgery. Neck support is not used after surgery.

\section{X-ray and clinical assessment}

The condition of VA was evaluated by preoperative magnetic resonance (MR) angiography. Surgical invasion, including surgical time and blood loss volume, were investigated. Radiographic measurements including atlantodens interval (ADI), space available for the cord (SAC), and Ranawat value were performed before surgery and at the follow-up. Clinical symptoms were studied before surgery and at the follow-up by measurement of the Japanese Orthopaedic Association (JOA) score and the Ranawat pain score [12]. Occipital and/or cervical pain was classified into four grades according to Ranawat's criteria, as follows: grade 0 , none; grade 1, mild (intermittent, requiring only aspirin analgesia); grade 2, moderate (cervical collar required); grade 3 , severe (pain not relieved by either aspirin or collar).

All patients underwent reconstruction CT scans (Siemens SOMATOM Sensation 16, Siemens Asahi Meditec Inc., Shinagawa, Tokyo, Japan) of instrumented levels one week after surgery. Transarticular screw perforations of atlantoaxial joints were evaluated by axial and sagittal CT images with $1.25 \mathrm{~mm}$ slice thickness. Screw perforation was defined, revealing that there was perforation of $50 \%$ or more of the screw diameter. Bony union and occurrence of postoperative subaxial subluxation was also evaluated. The criterion of bony fusion is as follows: ADI measured by dynamic lateral $\mathrm{X}$-ray is unchanged between maximum flexion and maximum extension. Sagittal reconstruction CT revealed no gap between the $\mathrm{C} 1$ lamina and graft bone and

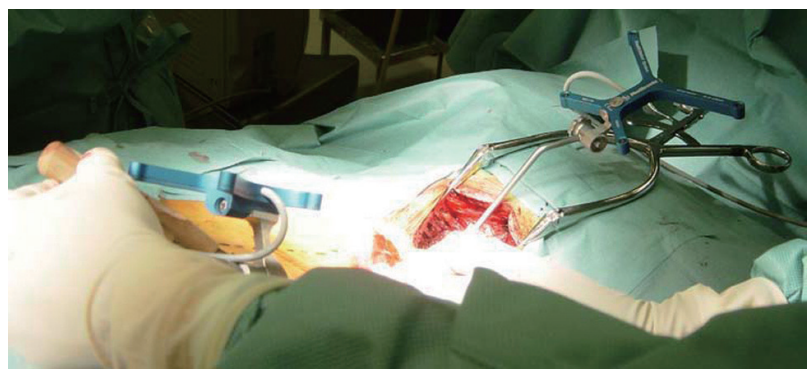

Fig. 2. At the screw insertion position, a small incision (approximately $1 \mathrm{~cm}$ ) was made and a guide for navigation was inserted. between the $\mathrm{C} 2$ lamina and graft bone.

The data were analyzed by paired-sample Student's t-tests using SPSS (SPSS Japan Inc., IBM company, Tokyo, Japan), with $p<0.05$ defined as significant.

\section{Results}

Preoperative MR angiography revealed two cases of right VA constriction and one case of left VA constriction, with "constriction" defined as $\leq 50 \%$ diameter of the VA.
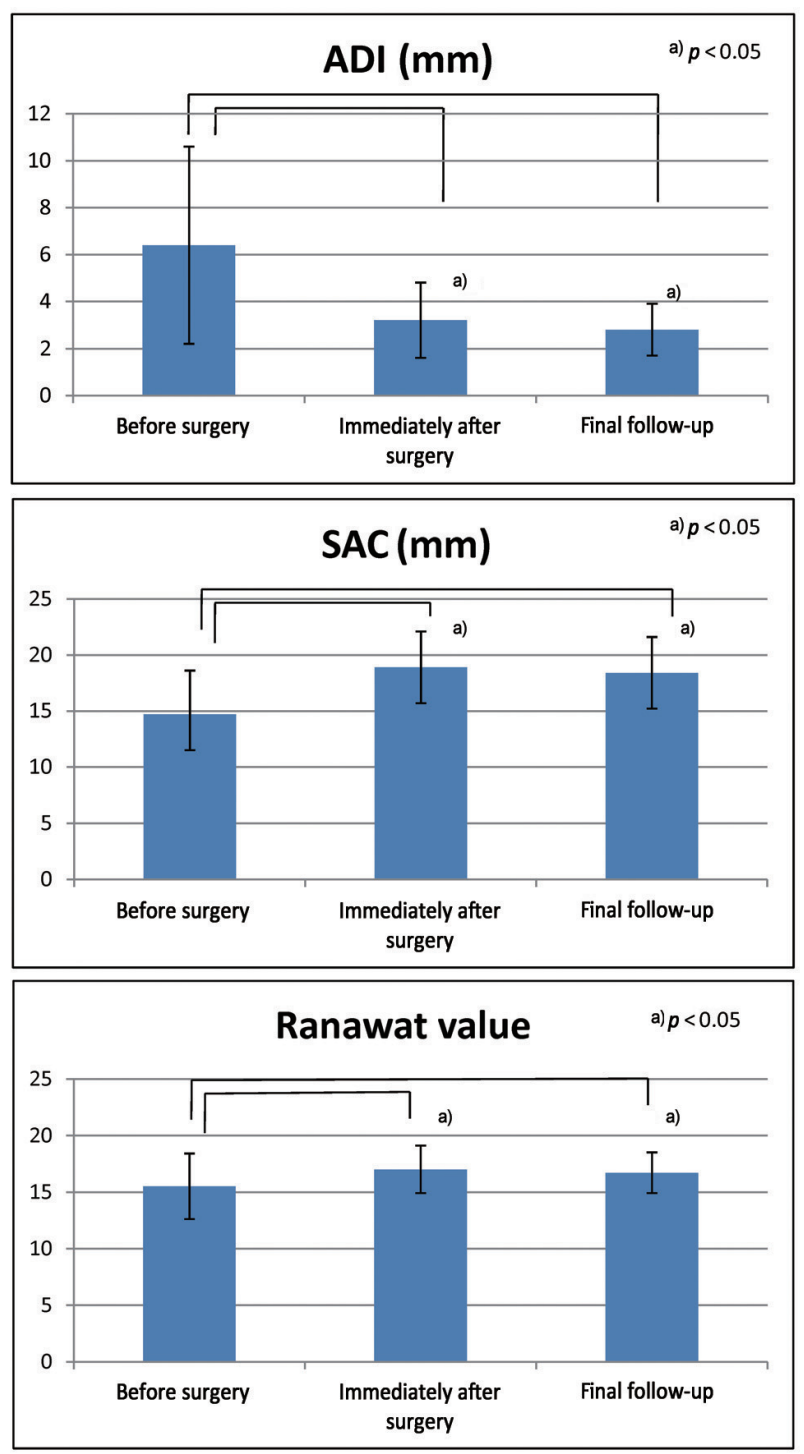

Fig. 3. Evaluations of preoperative and postoperative radiographs. At the final follow-up, atlantoaxial subluxation was corrected and all the average atlanto-dens interval (ADI), space available for the cord (SAC), and Ranawat values had improved. ADI showed significant improvement immediately after surgery $(p=0.0009)$ and at final follow-up ( $p=$ $0.0002)$. SAC showed significant improvement immediately after surgery $(p=0.0005)$ and at final follow-up $(p=0.001)$. 

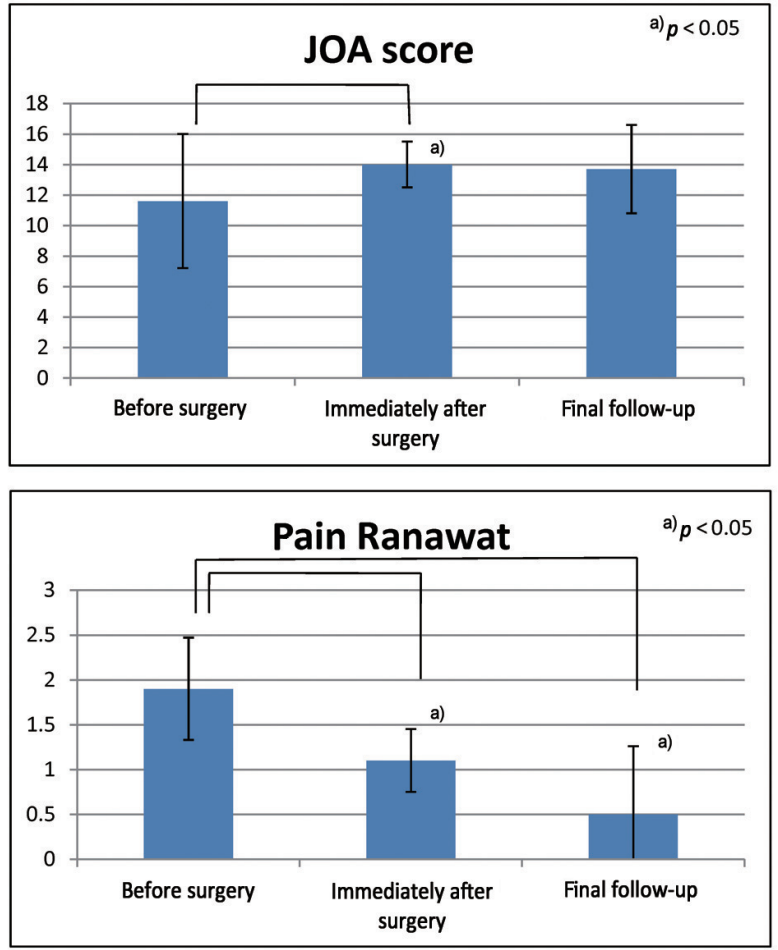

Fig. 4. Preoperative and postoperative patient's complaint. Both Japanese Orthopaedic Association (JOA) score and Ranawat pain score had improved postoperatively compared to those before surgery. Mean Ranawat pain score immediately after surgery was significantly improved $(p=0.004)$ and was maintained to the final follow-up $(p=0.001)$.
The patients' follow-up time ranged from 3 to 101 months (mean, $33.8 \pm 32.8$ months). The average surgical time was $205 \pm 76$ minutes (range, 123 to 328 minutes). The average blood loss volume was $242 \pm 168 \mathrm{ml}$ (range, 20 to $600 \mathrm{ml}$ ). Seven out of 20 patients underwent additional laminoplasty or laminectomy (Table 1).

Mean ADI values were as follows: before surgery, 6.4 $\pm 4.2 \mathrm{~mm}$; immediately after surgery, $3.2 \pm 1.6 \mathrm{~mm}$; at the final follow-up, $2.8 \pm 1.1 \mathrm{~mm}$. This showed significant improvement immediately after surgery $(p=0.0009)$ and at the final follow-up ( $p=0.0002)$, compared to before surgery. Mean SAC was as follows: before surgery, $14.7 \pm 3.9$ $\mathrm{mm}$; immediately after surgery, $18.9 \pm 3.2 \mathrm{~mm}$; at the final follow-up, $18.5 \pm 3.2 \mathrm{~mm}$. The mean SAC immediately after surgery was significantly improved $(p=0.0005)$ and was maintained up to the final follow-up $(p=0.001)$. Mean Ranawat values were as follows: before surgery, $15.5 \pm 2.9$ $\mathrm{mm}$; immediately after surgery, $17.0 \pm 2.1 \mathrm{~mm}(p=0.001)$; at the final follow-up, $16.7 \pm 1.8 \mathrm{~mm}(p=0.015)$ (Fig. 3).

The mean JOA score before and immediately after surgery was $11.6 \pm 4.4$ points (range, 1.5 to 15.5 points) and $14.0 \pm 1.5$ points (range, 12 to 16 points), respectively. At the final follow-up, the mean JOA score was $13.7 \pm 2.9$ points (range, 9 to 17 points). The mean JOA score immediately after surgery was significantly improved $(p=0.018)$. The mean Ranawat pain score before and immediately after surgery was $1.9 \pm 0.57$ (range, 1 to 3 ) and $1.1 \pm 0.35$ (range, 1 to 2). At the final follow-up, the mean Ranawat score was

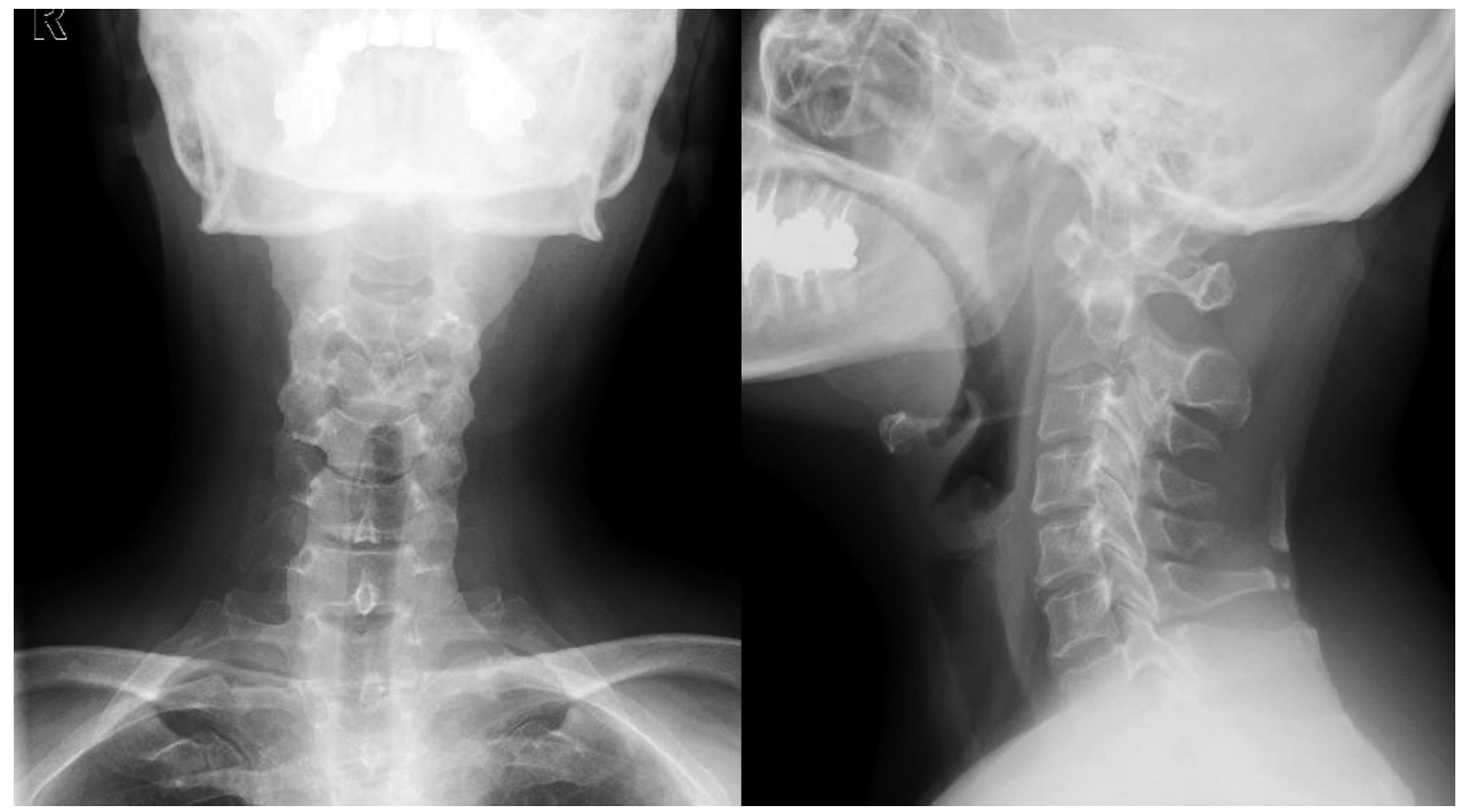

Fig. 5. Preoperative radiographs revealed atlanto-dens interval of $5 \mathrm{~mm}$, space available for the cord of $18 \mathrm{~mm}$, and atlantoaxial subluxation. 
$0.50 \pm 0.76$ (range, 0 to 2 ). The mean Ranawat pain score immediately after surgery was significantly improved ( $p=$ 0.004 ) and was maintained up to the final follow-up ( $p=$ 0.001) (Fig. 4).

The screw perforation rate was $2.6 \%$ (1/38). One screw caused lateral perforation but the screw was penetrated to the atlantoaxial joints. No newly developed neurologic deficits occurred after surgery. Neither spinal cord injuries nor spinal nerve root injuries were observed postoperatively. No VA injury was encountered. All patients who we were able to be followed up a year or more after surgery achieved bony fusion of the atlantoaxial joint. Subaxial subluxations were encountered after a mean period of 67.7 months (range, 60 to 75 months) after surgery in 3 patients. The subluxation level was $\mathrm{C} 2 / 3$ in 1 patient 75 months after surgery, and C3/4 in 2 patients 60 and 68 months after surgery. There was no deterioration of nerve symptoms due to subaxial subluxation.

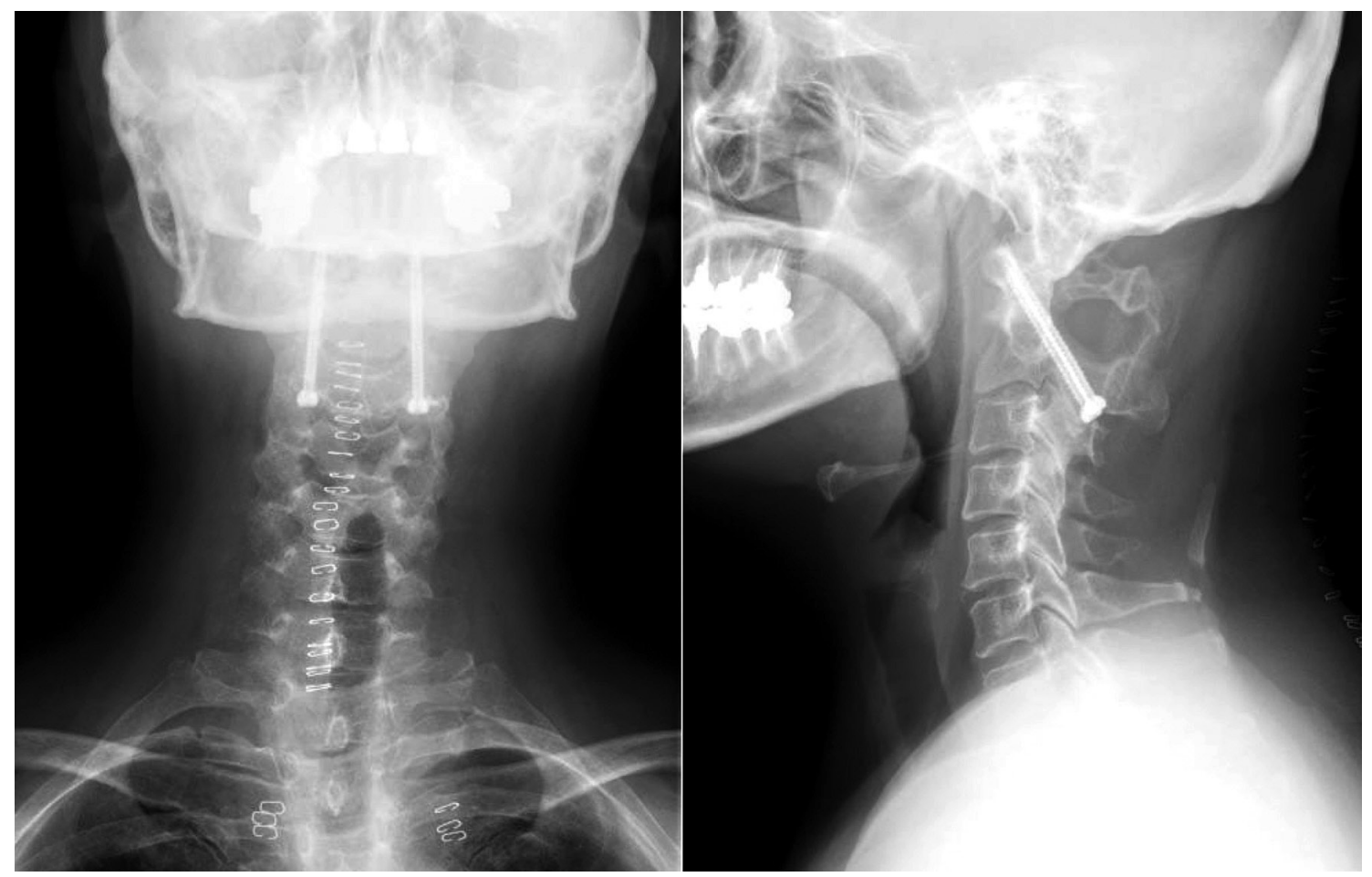

Fig. 6. Postoperative radiographs revealed accurate screw penetration and placement in favorable positions.
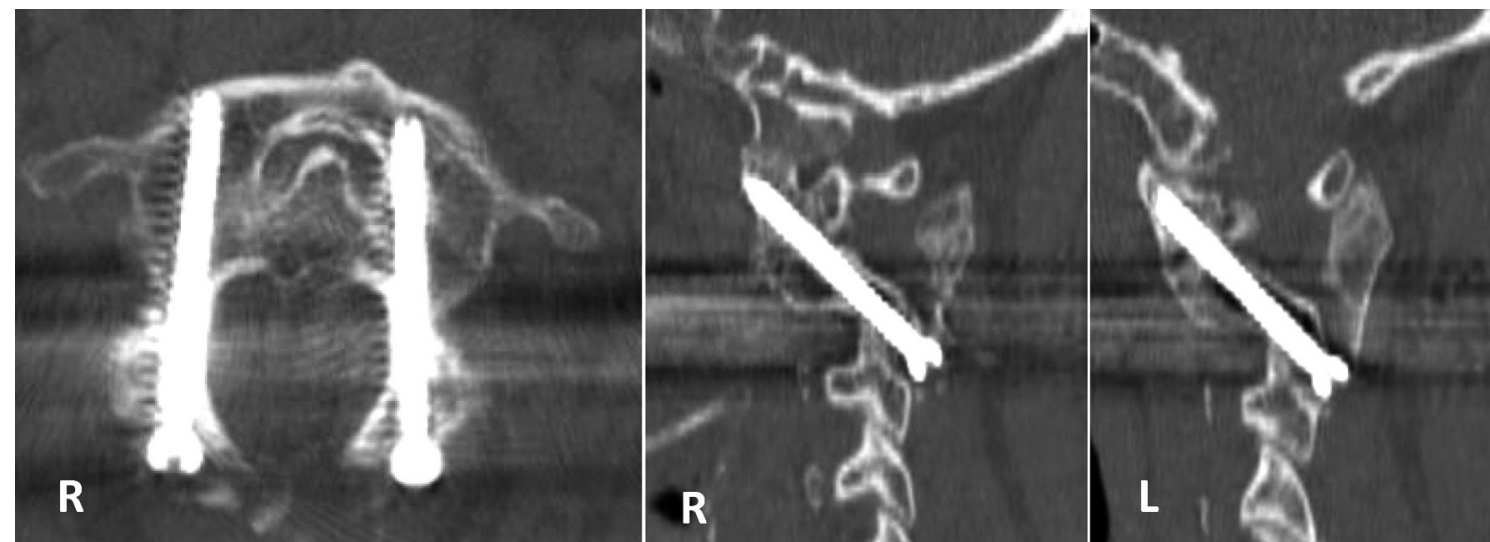

Fig. 7. Postoperative computed tomography scans revealed absence of penetration to transverse foramen and accurate screw insertion to the atlantoaxial joint. 


\section{Case presentation}

1) Case 9

A 51-year-old woman with AAS due to RA. Preoperative radiograph revealed ADI of $5 \mathrm{~mm}, \mathrm{SAC}$ of $18 \mathrm{~mm}$ (Fig. 5). Transarticular screw fixation (UCSS, Medtronic) was inserted using the CT-based navigation system and image intensifier, lateral view. A posterior bone graft was performed using the Brooks method using Secure Strand sublaminar cables (Pioneer Surgical Technology, Marquette, MI, USA). Postoperative radiograph revealed accurate penetration of the screw with a good position (Fig. 6). ASS was corrected and $\mathrm{ADI}$ was $3 \mathrm{~mm}$. By postoperative $\mathrm{CT}$, an axial image revealed an absence of transverse foramen perforation, and an oblique axial image, which was parallel to the screw, showed accurate screw insertion (Fig. 7). After 48 months post-surgery, there had been no instability of the atlantoaxial joint, and the patient showed improvement from grade 2 (preoperatively) to 0 by Ranawat's pain criteria (Fig. 8).

\section{Discussion}

Atlantoaxial instability results from aplasia or hypoplasia of the odontoid process, laxity of the transverse ligament, or assimilation of the atlas. It is associated with various conditions including RA, Down syndrome, Klippel-Feil syndrome, osteogenesis imperfect, and neurofibromatosis [13-17]. The indications for operation in patients with atlantoaxial instability are severe neck pain, myelopathy, progressive neurologic deficit, and reduction of the quality of life.

Spinal instrumentation surgery that achieves rigid fixation has been a great advantage for many patients; however, complications caused by screw insertion failure, including neurovascular injuries, have occurred. Many investigations on the risk of screw insertion have been performed for the atlantoaxial fusion by Magerl's procedure [18-20]. One reason for the risk of screw insertion is the variation in axis shape [21]. Also, the increased risk of VA injuries has been studied in cases with high-riding transverse foramen of axis (internal shift) accompanied with posterior shift, cases of residual severe subluxation, and cases of severe anterior subluxation complicated with severe lateral subluxation. The actual rate of VA tear in Magerl's procedure is as high as $2.4 \%$ to $5.8 \%$, and it is reported that $0.2 \%$ of cases result in major complications including cerebral infarction, and $0.1 \%$ result in death $[22,23]$.

Many reports have shown that, using a navigation system, pedicle screws can be inserted safely and accurately in surgery in the clinical setting [3,5-7] and in laboratory investigations $[4,24]$. There have been several reports describing the usefulness of this system in series of patients undergoing
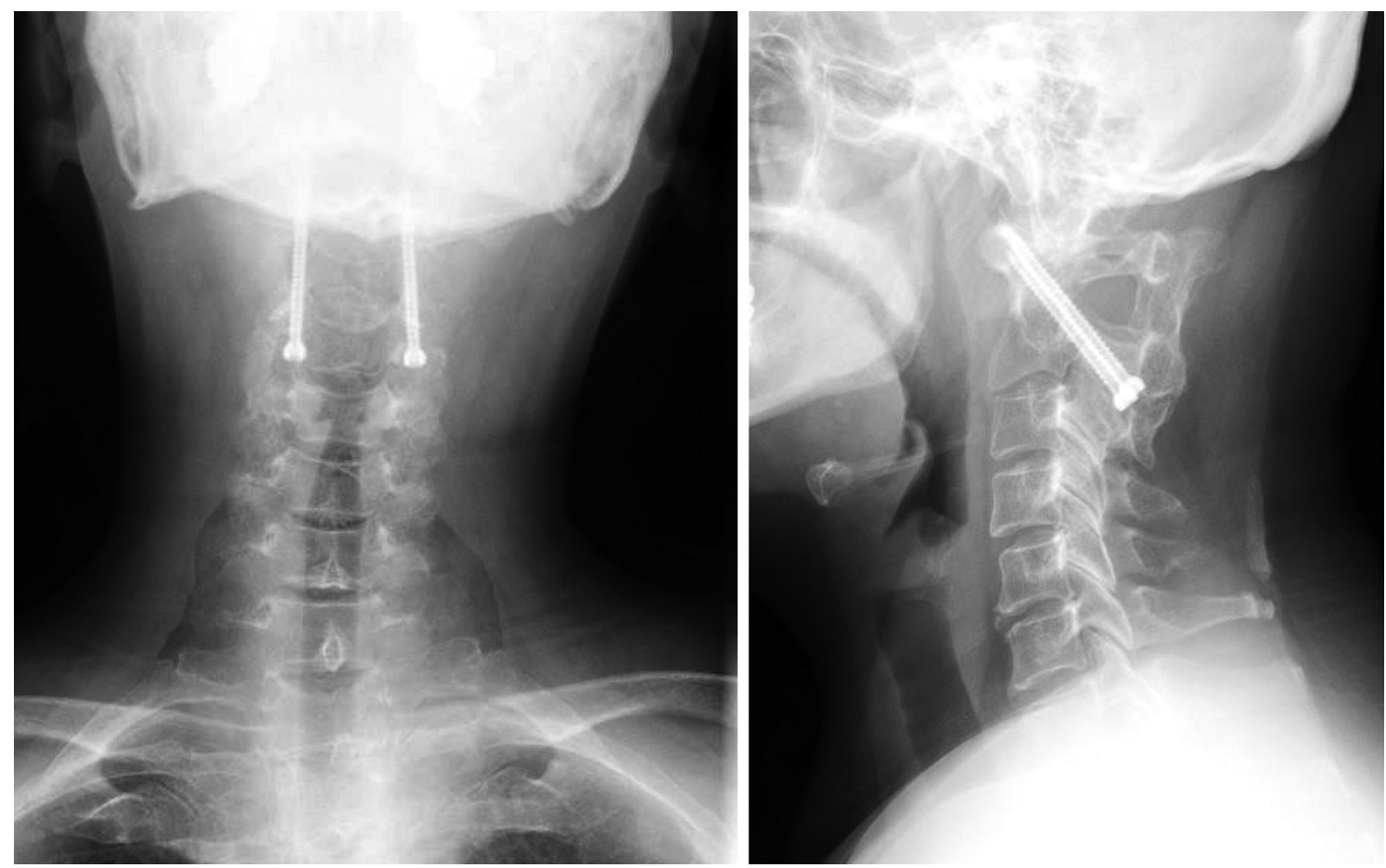

Fig. 8. Radiographs after 48 months postsurgery. Atlantoaxial joint was fused without instability. Radiographs show atlanto-dens interval of $3 \mathrm{~mm}$, space available for the cord of $20 \mathrm{~mm}$, and Ranawat value of $13 \mathrm{~mm}$. 
posterior atlantoaxial fixation using transpedicular screws with computer assistance [5,18,25-27] (Table 2).

Madawi et al. [21] reported a screw perforation rate of $14 \%$ ( 9 cases) and $8.2 \%$ of VA injury ( 5 cases) in subjects who underwent Magerl's procedure without CT-based navigation system. Suchomel et al. [28] collected the records of 80 patients for whom Magerl's procedure without CT-based navigation system was carried out and reported that the screw perforation rate was $17.3 \%$ and the risk of VA injury was $5 \%$. Our report showed better results compared with the previous reports.

Using the navigation system, cases for which the screw insertion was judged problematic are not inserted, and the complications can be prevented. However, single-sided screw insertion has a weaker fixation force, and the postoperative fitting of a halo vest is required in some cases. With the navigation system, three-dimensional images can be rotated on the screen, and observation from all angles is possible during planning. Through detailed investigation of slice planes, sometimes a route to insert the screw can be found, even in cases where screw insertion seems difficult, leading to an increase in the indications of Magerl's procedure.

As a limitation of the navigation system, only the areas that are fixed during surgery can be handled by the system, and if the intraoperative position is changed with respect to the preoperative in cases such as ASS, either the atlas or axis can still be navigated, but not both at the same time. To solve this drawback, we fitted the halo vest preoperatively and then obtained CT images to use as the basis for preoperative planning, then performed the surgery with the halo vest in place. Even when the halo vest was applied, the motion between $\mathrm{C} 1$ and $\mathrm{C} 2$ could not be controlled completely. However, the navigation system can reduce the high risk of tear of the vertebral artery, spinal cord, and nerve root when the screw is penetrating the $\mathrm{C} 2$ pedicle. We used a lateral image intensifier at the same time and performed the reduction of subluxation by pushing the $\mathrm{C} 2$ spinous process when the guide pin is penetrating the $\mathrm{C} 1 / 2$ joint, and inserting the guide pin into the $\mathrm{C} 1$ lateral mass. This procedure achieved significant improvement in SAC and the Ranawat pain score. Also, the screw perforation rate was low and complications were not observed. As a complication of atlantoaxial joint fusion, subluxation has been reported after long-term follow-up [29,30]. In the present study, 3 cases showed subaxial subluxation. However, neurological symptoms did not occur for these cases. As there is a possibility of the occur- 
rence of adverse effects of the procedure that may become observable only after a longer period, we perform a careful follow-up to reduce the influence of these effects.

In this study, all cases showed postoperative relief of clinical symptoms. The accuracy of Magerl's procedure was improved by the use of the navigation system. The navigation system proved to be a useful support device for avoiding intraoperative complications, and surgery was sometimes found feasible even in cases that had been evaluated as difficult to perform. However, navigation is still not possible for the cases with intraoperative change or flexible intervertebral points. Also, risks caused by the deviation of screw insertion resulting from incorrect hand movement by the operator or by failure to observe the surgical field during monitor screen observation still remain.

There are some limitations of this surgical procedure. First, applying a halo vest three or four days before surgery could make patients uncomfortable. Second, it is not easy to drape or take position of a patient with a halo vest. Lastly, though preoperative reduction is needed before CT scanning, it is not easy to obtain satisfactory reduction in the case of severe atlantoaxial instability that requires a navigation system. Furthermore, one of the limitations of this study is that there are 6 cases with 6-month or less follow-up. Another limitation is that seven out of 20 patients underwent additional laminoplasty or laminectomy, and this could act as a confounding factor in the analysis of the JOA score and Ranawat pain score. However, the use of the CT navigation system during Magerl's procedure improved the accuracy of insertion and proved useful for cases that present difficulty in treatment, showing favorable outcomes. Improvement of the navigation system and development of systems that are easier to use are necessary in the future.

\section{Conclusions}

The CT-based navigation system has been demonstrated to be an effective support device for Magerl's procedure.

\section{REFERENECES}

1. Magerl F, Seemann PS. Stable posterior fusion of the atlas and axis by transarticular screw fixation. In: Kehr P, Weidner A; Cervical Spine Research Society, editors. Cervical spine 1. Vienna (AT): Springer-Verlag; 1987. p. 322-7.

2. Golfinos JG, Fitzpatrick BC, Smith LR, Spetzler RF.
Clinical use of a frameless stereotactic arm: results of 325 cases. J Neurosurg 1995;83:197-205.

3. Amiot LP, Labelle H, DeGuise JA, Sati M, Brodeur P, Rivard CH. Computer-assisted pedicle screw fixation. A feasibility study. Spine (Phila Pa 1976) 1995;20:120812.

4. Nolte LP, Zamorano LJ, Jiang Z, Wang Q, Langlotz F, Berlemann U. Image-guided insertion of transpedicular screws. A laboratory set-up. Spine (Phila Pa 1976) 1995;20:497-500.

5. Bolger C, Wigfield C. Image-guided surgery: applications to the cervical and thoracic spine and a review of the first 120 procedures. J Neurosurg 2000;92:175-80.

6. Kamimura M, Ebara S, Itoh H, Tateiwa Y, Kinoshita T, Takaoka K. Cervical pedicle screw insertion: assessment of safety and accuracy with computer-assisted image guidance. J Spinal Disord 2000;13:218-24.

7. Ludwig SC, Kowalski JM, Edwards CC 2nd, Heller JG. Cervical pedicle screws: comparative accuracy of two insertion techniques. Spine (Phila Pa 1976) 2000;25:2675-81.

8. Richter M, Amiot LP, Neller S, Kluger P, Puhl W. Computer-assisted surgery in posterior instrumentation of the cervical spine: an in-vitro feasibility study. Eur Spine J 2000;9 Suppl 1:S65-70.

9. Takahashi J, Hirabayashi H, Hashidate H, Ogihara N, Kato H. Accuracy of multilevel registration in imageguided pedicle screw insertion for adolescent idiopathic scoliosis. Spine (Phila Pa 1976) 2010;35:347-52.

10. Uehara M, Takahashi J, Hirabayashi H, et al. Perforation rates of cervical pedicle screw insertion by disease and vertebral level. Open Orthop J 2010;4:142-6.

11. Ogihara N, Takahashi J, Hirabayashi H, Hashidate H, Mukaiyama K, Kato H. Stable reconstruction using halo vest for unstable upper cervical spine and occipitocervical instability. Eur Spine J 2012;21:295-303.

12. Takahashi J, Shono Y, Nakamura I, et al. Computerassisted screw insertion for cervical disorders in rheumatoid arthritis. Eur Spine J 2007;16:485-94.

13. Ranawat CS, O'Leary P, Pellicci P, Tsairis P, Marchisello P, Dorr L. Cervical spine fusion in rheumatoid arthritis. J Bone Joint Surg Am 1979;61:1003-10.

14. Crockard HA, Stevens JM. Craniovertebral junction anomalies in inherited disorders: part of the syndrome or caused by the disorder? Eur J Pediatr 1995;154:50412.

15. Isu T, Miyasaka $\mathrm{K}$, Abe $\mathrm{H}$, et al. Atlantoaxial disloca- 
tion associated with neurofibromatosis. Report of three cases. J Neurosurg 1983;58:451-3.

16. Mummaneni PV, Haid RW. Atlantoaxial fixation: overview of all techniques. Neurol India 2005;53:408-15.

17. Pellicci PM, Ranawat CS, Tsairis P, Bryan WJ. A prospective study of the progression of rheumatoid arthritis of the cervical spine. J Bone Joint Surg Am 1981;63:342-50.

18. Kawaguchi Y, Ishihara H, Ohmori K, Kanamori M, Kimura T. Computer-assisted Magerl's transarticular screw fixation for atlantoaxial subluxation. J Orthop Sci 2002; 7:131-6.

19. Herz T, Franz A, Giacomuzzi SM, Bale R, Krismer M. Accuracy of spinal navigation for magerl screws. Clin Orthop Relat Res 2003;(409):124-30.

20. Paramore CG, Dickman CA, Sonntag VK. The anatomical suitability of the C1-2 complex for transarticular screw fixation. J Neurosurg 1996;85:221-4.

21. Madawi AA, Casey AT, Solanki GA, Tuite G, Veres R, Crockard HA. Radiological and anatomical evaluation of the atlantoaxial transarticular screw fixation technique. J Neurosurg 1997;86:961-8.

22. Jeanneret B, Magerl F, Stanisic M. Thrombosis of the vertebral artery. A rare complication following traumatic spondylolisthesis of the second cervical vertebra. Spine (Phila Pa 1976) 1986;11:179-82.

23. Wright NM, Lauryssen C. Vertebral artery injury in C1-2 transarticular screw fixation: results of a survey of the AANS/CNS section on disorders of the spine and peripheral nerves. American Association of Neurological Surgeons/Congress of Neurological Surgeons. J Neurosurg 1998;88:634-40.

24. Kamimura M, Ebara S, Itoh H, Tateiwa Y, Kinoshita T, Takaoka K. Accurate pedicle screw insertion under the control of a computer-assisted image guiding system: laboratory test and clinical study. J Orthop Sci 1999;4:197-206.

25. Welch WC, Subach BR, Pollack IF, Jacobs GB. Frameless stereotactic guidance for surgery of the upper cervical spine. Neurosurgery 1997;40:958-63.

26. Acosta FL Jr, Quinones-Hinojosa A, Gadkary CA, et al. Frameless stereotactic image-guided C1-C2 transarticular screw fixation for atlantoaxial instability: review of 20 patients. J Spinal Disord Tech 2005;18:385-91.

27. Weidner A, Wahler M, Chiu ST, Ullrich CG. Modification of C1-C2 transarticular screw fixation by imageguided surgery. Spine (Phila Pa 1976) 2000;25:266873.

28. Suchomel P, Stulik J, Klézl Z, et al. Transarticular fixation of C1-C2: a multicenter retrospective study. Acta Chir Orthop Traumatol Cech 2004;71:6-12.

29. Ito H, Neo M, Sakamoto T, Fujibayashi S, Yoshitomi H, Nakamura T. Subaxial subluxation after atlantoaxial transarticular screw fixation in rheumatoid patients. Eur Spine J 2009; 18:869-76.

30. Yoshimoto $\mathrm{H}$, Ito $\mathrm{M}$, Abumi $\mathrm{K}$, et al. A retrospective radiographic analysis of subaxial sagittal alignment after posterior C1-C2 fusion. Spine (Phila Pa 1976) 2004;29:175-81.

31. Finn MA, Apfelbaum RI. Atlantoaxial transarticular screw fixation: update on technique and outcomes in 269 patients. Neurosurgery 2010;66:184-92.

32. Nagaria J, Kelleher MO, McEvoy L, Edwards R, Kamel MH, Bolger C. C1-C2 transarticular screw fixation for atlantoaxial instability due to rheumatoid arthritis: a seven-year analysis of outcome. Spine (Phila Pa 1976) 2009;34:2880-5. 